\title{
OBITUARY
}

\section{R. de Kérallain}

Le 5 septembre 1928 est mort, dans sa $79^{\circ}$ année, M. René Prigent de Kérallain qui, plus que tout autre, a utilement travaillé à faire connaître en France des écrivains qui sont parmi les plus distingués de la Grande Bretagne. Il a traduit, avec un rare bonheur de vocabulaire et de syntaxe, le livre de Frederick Pollock, Introduction à l'étude de la science politique, les ouvrages de H. Summer-Maive, Essais sur le gouvernement populaire, Etudes sur l'histoire du droit, Le droit international, La guerre. Mais son livre de prédilection fut les Asiatic Studies d'Alfred Lyall avec lequel il entretint une longue et intime amitié. Sa traduction, sous le titre Etudes sur les mours religieuses et sociales de l'Extrême-Orient, contient des introductions et des notes du plus grand mérite. ${ }^{1}$ M. de Kérallain laisse beaucoup d'ouvrages et de notes sur l'histoire ancienne et moderne du droit et de la navigation : il était le neveu de Bougainville. Personne en France n'a mieux connu l'anglais et l'Inde ; personne n'a mis, au service d'idées plus saines, un esprit plus incisif. La mort de Barth, dont il fut longtemps, en sa Bretagne, le compagnon, avait été pour lui une perte cruelle.

L. V. P.

1 Tous ces ouvrages dans Bibliothèque de l'Histoire du Droit et des Institutions, E. de Boccard, 1 rue de Médicis, Paris. 